\title{
Factors associated with not using folic acid supplements preconceptionally
}

\author{
Judith Manniën ${ }^{1, *}$, Ank de Jonge ${ }^{1}$, Martina $C$ Cornel $^{2}$, Evelien Spelten ${ }^{1}$ \\ and Eileen K Hutton ${ }^{1,3}$ \\ 'Department of Midwifery Science, AVAG and the EMGO Institute for Health and Care Research, VU University \\ Medical Center, Van der Boechorststraat 7 (MF-D4.44), 1081 BT Amsterdam, The Netherlands: ${ }^{2}$ Clinical \\ Genetics and EMGO Institute for Health and Care Research, VU University Medical Center, Amsterdam, \\ The Netherlands: ${ }^{3}$ Faculty of Health Sciences, McMaster University, Hamilton, Ontario, Canada
}

Submitted 30 May 2013: Final revision received 13 August 2013: Accepted 28 August 2013: First published online 10 October 2013

\begin{abstract}
Objective: Neural tube defects are among the most common birth defects worldwide. Folic acid intake from one month before to three months after conception reduces the likelihood of neural tube defects by at least $50 \%$. Since 1995 , several campaigns have been organised in the Netherlands which resulted in $51 \%$ of pregnant women using folic acid supplements during the entire recommended period in the northern part of the Netherlands in 2005. Our research question was to gain insight into the current prevalence and factors associated with inadequate pregnancy-related use of folic acid supplements.

Design: Data from the DELIVER study were used, which is a population-based cohort study.

Setting: Twenty midwifery practices across the Netherlands in 2009 and 2010.

Subjects: In total 5975 pregnant women completed a questionnaire covering items on sociodemographic and lifestyle factors, including folic acid intake.

Results: Of our study population, 55.5\% (3318/5975) used folic acid supplements before conception. Several sociodemographic and lifestyle factors were associated with no preconception use of folic acid, of which non-Western ethnicity and not having a partner had the largest effect size.

Conclusions: In the Netherlands, the folic acid intake before conception is suboptimal and has not improved over recent years. Fortification of staple foods with folic acid should be reconsidered as it would provide a more effective means of ensuring an adequate intake, especially for those groups of women who are unlikely to plan their pregnancies or to receive or respond to health promotion messages.
\end{abstract}

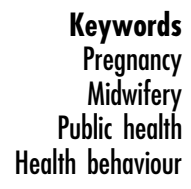

Keywords

Pregnancy

Public health

Health behaviour
Neural tube defects (NTD) result from the incomplete closure of the neural tube and constitute an important public health problem in terms of mortality, morbidity, societal cost and human suffering ${ }^{(1,2)}$. NTD are among the most common category of birth defects worldwide ${ }^{(3)}$. In Europe, more than 5100 pregnancies are affected by an NTD every year, i.e. $7 \cdot 7$ per 10000 pregnancies and $2 \cdot 8$ per 10000 live births ${ }^{(4)}$. For the Netherlands, the prevalence of NTD was estimated to be $8 \cdot 1$ per 10000 pregnancies in $2008^{(5)}$. Since the 1990s, randomised controlled trials and other studies have shown that intake of folic acid from one month before to three months after conception reduces the prevalence of NTD by at least $50 \%{ }^{(6-8)}$.

In order to increase the awareness and use of folic acid in the Netherlands, a government-sponsored national mass media campaign was executed in 1995 . The goal of the Ministry of Health was to achieve a $70 \%$ supplementation use by $2010^{(9)}$. Additionally, since 2004, Dutch pharmacies have been carrying out an ongoing proactive intervention by means of a sticker on oral contraceptives packages with the text 'Want a baby? Ask about folic acid at your pharmacy' and by providing a brochure with more detailed information about folic acid ${ }^{(10)}$. In the northern part of the Netherlands, the campaigns resulted in $51 \%$ of pregnant women using folic acid supplements during the entire recommended period (i.e. one month before to three months after conception) in 2005, but this percentage was much lower among lower-educated women $(31 \%)^{(10)}$. In the multi-ethnic populations of Amsterdam and Rotterdam, respectively only $40 \%$ and $37 \%$ of women used folic acid as recommended in 2002-2006 ${ }^{(11,12)}$. In most other European countries, the periconceptional use of folic acid does not reach $10 \%{ }^{(13)}$. There is still considerable scope for improving folic acid intake, with potentially preventable NTD cases occurring each year. 
Previous studies have shown that sociodemographic factors influence periconceptional folic acid intake. Inadequate folic acid intake was associated with younger age, lower education, low household income, low socioeconomic status, living in a deprived area, immigrant status, single marital status, multiparity, unplanned pregnancy, smoking and alcohol use ${ }^{(12,14-19)}$. However, a systematic review showed that study quality was often poor. Most studies were small and were conducted late in pregnancy or even after delivery, which led to a high risk of recall bias, and most studies only used univariable analyses ${ }^{(18)}$.

The most recent data on folic acid use in the Netherlands derive from studies in 2003-2004 and 1995-2005. However, the former study was conducted in one large city with many low-educated women and women of non-Western background ${ }^{(11)}$, and the latter study took place only in the northern part of the country ${ }^{(10)}$.

The DELIVER study is a population-based cohort study conducted among a large number of women who received care in twenty midwifery practices across the Netherlands in 2009 and 2010. These data were used to provide national baseline data on folic acid use and factors associated with its use in order to determine the potential to improve the use of folic acid supplements. We studied sociodemographic and lifestyle factors associated with not using folic acid preconceptionally.

\section{Methods}

\section{Study design and population}

We used data from the national DELIVER study, which is a multi-centre prospective population-based cohort study to evaluate primary-care midwifery in the Netherlands with the main focus on quality, organisation and accessibility of care. The design of the study is described elsewhere and summarised here ${ }^{(20)}$. Between September 2009 and December 2010, data were collected from clients and midwives within twenty midwifery practices across the Netherlands. These twenty practices were recruited from the total of 519 primary-care practices in the Netherlands via purposive sampling using three stratification criteria: region (north, east, south, west), level of urbanisation (urban or rural) and practice type (dual or group practice). The twenty participating practices comprised 108 midwives and about 8200 clients per year. The client recruitment period at each midwifery practice was 12 months. All consecutive clients were invited to participate if they were able to understand Dutch, English, Turkish or Arabic. Clients received up to three questionnaires, depending on their gestational age at inclusion. For the present study, data from the first questionnaire were used which was completed before 35 weeks' gestation and included information on health and lifestyle (including folic acid intake) and on
Table 1 Questions regarding the intake of folic acid supplements

\begin{tabular}{ll}
\hline Question & Answering options \\
\hline $\begin{array}{l}\text { 1. Have you been taking a daily } \\
\text { folic acid supplement because } \\
\text { of the current pregnancy? }\end{array}$ & b. Yes \\
$\begin{array}{ll}\text { 2. If yes: When did you begin } \\
\text { taking a folic acid supplement? }\end{array}$ & $\begin{array}{l}\text { a. ..... weeks before stopping } \\
\text { contraception }\end{array}$ \\
& $\begin{array}{l}\text { b. At the same time as } \\
\text { stopping contraception } \\
\text { c. ..... weeks after stopping } \\
\text { contraception }\end{array}$ \\
& $\begin{array}{l}\text { d. When I suspected that } \\
\text { I might be pregnant } \\
\text { e. When I knew for certain } \\
\text { I was pregnant }\end{array}$ \\
& f. Other, ............ \\
\hline
\end{tabular}

sociodemographic characteristics of the women. Table 1 shows how information on folic acid use was asked in the questionnaire.

\section{Study measures}

To determine the prevalence of and factors associated with folic acid use, we included only women who completed the questions regarding folic acid supplement use in the first questionnaire. The folic acid intake was dichotomised. Clients were assigned to the group 'preconception use' if they indicated that they used folic acid and began use before conception (question 2, item $\mathrm{a}, \mathrm{b}$ or $\mathrm{c}$ ). Clients were assigned to the group "no preconception use' if they indicated that they used folic acid and began use after conception (question 2, item d or e) or if they had not been taking a daily folic acid supplement during the current pregnancy. Comments provided by women in response to the open-ended question (2f: 'other') were also used to assign them to one of the two groups.

The following lifestyle and sociodemographic characteristics were considered to be possibly related to not taking folic acid supplements preconceptionally, based on the literature ${ }^{(12,14-19)}$ : age ( $\leq 25$ years/26-30 years/31-35 years/ $\geq 36$ years), parity (nulliparous/multiparous), ethnicity (Dutch/Western/non-Western), educational level (low/ medium/high), paid job last year (yes/no), having a partner (yes/no), religion, self-identified general state of health (excellent or (very) good/moderate or poor), alcohol used during pregnancy (yes/no), smoked during pregnancy (yes/no), pre-pregnancy BMI $\left(<25 \mathrm{~kg} / \mathrm{m}^{2} / 25-30 \mathrm{~kg} / \mathrm{m}^{2} /\right.$ $\geq 30 \mathrm{~kg} / \mathrm{m}^{2}$ ), self-reported physical activity (number of days per week $>30 \mathrm{~min}$ ), and the extent to which women feel that they can influence their health by changing their lifestyles and/or behaviour (not at all or hardly/quite a lot or a lot). Ethnicity was based on the definition used by Statistics Netherlands, which considers someone to be of non-Dutch ethnicity if at least one of the parents was born in a country other than the Netherlands ${ }^{(21)}$. We made a distinction between Dutch ethnicity, other 
Western ethnicity (Europe (excluding Turkey), North America, Oceania, Indonesia and Japan) and non-Western ethnicity (Turkey, Africa, Latin America and Asia (excluding Indonesia and Japan)) according to the definition used by Statistics Netherlands. Educational level was defined, depending on the highest level of achievement, as low (medium-level secondary education or below), medium (higher-level secondary education or vocational education) or high (diploma-level or university education). The respondents were also asked if they identified themselves with a religious group or ideology, and if so, which one. Religion was then divided into four categories: 'none' (none/not applicable/don't know/don't want to say), 'Catholic', 'Protestant' and 'other' (Humanism, Islam, Judaism, Hinduism, Buddhism). Physical activity was measured as the number of days per week that a woman was physically active for at least $30 \mathrm{~min}$, which was dichotomised into $<5 \mathrm{~d} /$ week and $\geq 5 \mathrm{~d}$ /week. Data from the Perinatal Registry Netherlands and from Statistics Netherlands were used to compare some of the characteristics of our population with the national population.

\section{Statistical analyses}

Descriptive analyses were used to describe characteristics of the study population. Associations between no preconception use of folic acid supplements and lifestyle and sociodemographic factors were estimated by odds ratios and $95 \%$ confidence intervals obtained by binary logistic regression. Variables with a $P$ value below $0 \cdot 10$ in the univariable analysis were considered for the multivariable analysis. From an initial multivariable model, variables were sequentially removed through backward selection. In each step, the variable with the largest $P$ value was removed until the model contained only statistically significant variables (two-sided $P<0 \cdot 05$ ). Due to the fact that the respondents in the study population were clustered within twenty midwife practices, multilevel analysis was carried out to account for any possible effects due to differences between practices. Records with missing values for any of the independent variables in the final model were excluded. Descriptive and regression analyses were carried out using the IBM SPSS statistical software package version $20 \cdot 0$. The statistical software package STATA version 10 was used for the multilevel analyses.

\section{Results}

The response rate of the DELIVER study was $62 \%{ }^{(20)}$. Of all 7685 clients who participated in the DELIVER study, 6046 completed the first questionnaire. Seventyone clients were excluded because we could not determine their folic acid use by their comments provided in response to the open-ended question (2f: 'other'). Characteristics of the remaining 5975 clients are described in Table 2. Comparison with the national population revealed that our study population was representative for parity (nulliparous: $46 \%$ our data $v .47 \%$ national) and age (26-35 years: $73 \%$ v. 69\%), but comprised more highly educated women ( $49 \% v .42 \%)$ and fewer ethnic minority women $(16 \% v .25 \%)$. At the time of completing the questionnaire, the median gestational age of the clients was 19 weeks (10th centile: 13 weeks; 90th centile: 29 weeks).

Of our study population, 91.3\% (5457/5975) used folic acid supplements at any time during pregnancy and $55 \cdot 5 \%$ ( $n$ 3318) started using folic acid before conception. Thus, $44.5 \%$ did not take folic acid supplements before conception. Results of univariable analysis of factors related to no preconception use of folic acid are shown in Table 2. Factors related to the highest rates of not using folic acid before conception were not having a partner (78.8\% no preconception folic acid use), religion other than Catholic or Protestant $(73.6 \%)$, non-Western ethnicity $(71 \cdot 1 \%)$ and being unemployed $(69 \cdot 2 \%)$.

Results of the multilevel multivariable logistic regression analysis are shown in Table 3. No preconception use of folic acid was more often observed among women of ethnic minority background, who were unemployed, had no partner, were younger than 25 years compared with 26-35 years, were multiparous, had a religion other than Catholic, or had a low or medium level of education. In addition, the odds for no preconception use of folic acid supplements was higher for women who smoked during pregnancy, drank alcohol during pregnancy, had a general moderate or poor health status, or believed that they could not at all or hardly influence their own health. BMI, level of physical activity and region within the country were not independently associated with preconception use of folic acid supplements.

\section{Discussion}

Results of the multi-centre prospective DELIVER study showed that in 2009 and $2010,44.5 \%$ of pregnant women in the Netherlands did not start using folic acid supplements before conception. This folic acid intake is better than in most other European countries, where more than $90 \%$ of women do not take folic acid supplements periconceptionally ${ }^{(13)}$. The aim of a former Dutch government to reach $70 \%$ adequate folic acid supplementation use by 2010 has not been reached ${ }^{(9)}$. It seems that the use of folic acid supplements has not increased any further since the successful campaigns in 1995 and 2004, which resulted in an adequate folic acid intake rate of $51 \%$ in 2005 in the northern part of the Netherlands ${ }^{(10)}$. As rates of NTD have not declined as much as expected and folic acid is known to be very effective in preventing them ${ }^{(22)}$, more effort should be put into increasing adequate intake of folic acid before and immediately after conception. 
Table 2 Univariable associations between lifestyle and sociodemographic characteristics of pregnant women who did not start taking folic acid supplements before conception; DELIVER multi-centre, prospective, population-based cohort study, the Netherlands, 2009 and 2010

\begin{tabular}{|c|c|c|c|c|c|}
\hline \multirow[b]{2}{*}{ Characteristic } & \multirow[b]{2}{*}{ Total $N^{*}$} & \multicolumn{2}{|c|}{ No preconception use of folic acid } & \multirow[b]{2}{*}{ OR } & \multirow[b]{2}{*}{$95 \% \mathrm{Cl}$} \\
\hline & & $n$ & $\%$ & & \\
\hline Overall & 5975 & 2657 & $44 \cdot 5$ & & \\
\hline \multicolumn{6}{|l|}{ Age } \\
\hline$\leq 25$ years & 838 & 522 & $62 \cdot 3$ & $2 \cdot 4$ & $2 \cdot 1,2 \cdot 8+$ \\
\hline $26-35$ years & 4340 & 1755 & $40 \cdot 0$ & $1 \cdot 0$ & Ref. \\
\hline$\geq 36$ years & 791 & 376 & $47 \cdot 5$ & $1 \cdot 3$ & $1 \cdot 1,1 \cdot 6+$ \\
\hline \multicolumn{6}{|l|}{ Partner } \\
\hline Yes & 5871 & 2578 & $43 \cdot 9$ & $1 \cdot 0$ & Ref. \\
\hline No & 99 & 78 & $78 \cdot 8$ & $4 \cdot 7$ & $2 \cdot 9,7 \cdot 7 \dagger$ \\
\hline \multicolumn{6}{|l|}{ Ethnicity } \\
\hline Dutch & 4999 & 2049 & $41 \cdot 0$ & $1 \cdot 0$ & Ref. \\
\hline Other Western & 449 & 240 & $53 \cdot 5$ & $1 \cdot 7$ & $1 \cdot 4,2 \cdot 0+$ \\
\hline Non-Western & 506 & 360 & $71 \cdot 1$ & $3 \cdot 6$ & $2 \cdot 9,4 \cdot 3+$ \\
\hline \multicolumn{6}{|l|}{ Religion } \\
\hline None/don't want to say & 3584 & 1423 & $39 \cdot 7$ & $1 \cdot 0$ & Ref. \\
\hline Catholic & 623 & 255 & $40 \cdot 9$ & $1 \cdot 1$ & $0 \cdot 9,1 \cdot 3$ \\
\hline Protestant & 1388 & 700 & $50 \cdot 4$ & $1 \cdot 5$ & $1 \cdot 4,1 \cdot 8+$ \\
\hline Other $\ddagger$ & 360 & 265 & $73 \cdot 6$ & $4 \cdot 2$ & $3 \cdot 3,5 \cdot 4 t$ \\
\hline \multicolumn{6}{|l|}{ Educational level } \\
\hline Low & 897 & 540 & $60 \cdot 2$ & $2 \cdot 6$ & $2 \cdot 2,3 \cdot 0+$ \\
\hline Medium & 2147 & 1025 & $47 \cdot 7$ & $1 \cdot 5$ & $1 \cdot 4,1 \cdot 7 \dagger$ \\
\hline High & 2924 & 1087 & $37 \cdot 2$ & $1 \cdot 0$ & Ref. \\
\hline \multicolumn{6}{|l|}{ Employed } \\
\hline Yes & 5104 & 2055 & $40 \cdot 3$ & $1 \cdot 0$ & Ref. \\
\hline No & 864 & 598 & $69 \cdot 2$ & $3 \cdot 3$ & $2 \cdot 9,3 \cdot 9+$ \\
\hline \multicolumn{6}{|l|}{ Region } \\
\hline North & 1494 & 644 & $43 \cdot 1$ & $1 \cdot 0$ & $0.9,1 \cdot 2$ \\
\hline East & 1813 & 775 & $42 \cdot 7$ & $1 \cdot 0$ & $0 \cdot 8,1 \cdot 2$ \\
\hline South & 866 & 372 & $43 \cdot 0$ & $1 \cdot 0$ & Ref. \\
\hline West & 1802 & 866 & $48 \cdot 1$ & $1 \cdot 2$ & $1 \cdot 0,1 \cdot 4 t$ \\
\hline \multicolumn{6}{|l|}{ Parity } \\
\hline Nulliparous & 2729 & 1067 & $39 \cdot 1$ & $1 \cdot 0$ & Ref. \\
\hline Multiparous & 3232 & 1584 & $49 \cdot 0$ & 1.5 & $1 \cdot 4,1 \cdot 7 \dagger$ \\
\hline \multicolumn{6}{|l|}{ General state of health } \\
\hline Excellent or (very good) & 5243 & 2271 & $43 \cdot 3$ & $1 \cdot 0$ & Ref. \\
\hline Moderate or poor & 728 & 385 & $52 \cdot 9$ & 1.5 & $1 \cdot 3,1 \cdot 7 \dagger$ \\
\hline \multicolumn{6}{|c|}{ Ability to influence own health } \\
\hline Quite a lot or a lot & 5060 & 2113 & $41 \cdot 8$ & $1 \cdot 0$ & Ref. \\
\hline \multirow{2}{*}{\multicolumn{6}{|c|}{ Smoking during pregnancy }} \\
\hline & & & & & \\
\hline No & 5426 & 2316 & $42 \cdot 7$ & $1 \cdot 0$ & Ref. \\
\hline Yes & 549 & 341 & $62 \cdot 1$ & $2 \cdot 2$ & $1 \cdot 8,2 \cdot 6 \dagger$ \\
\hline \multicolumn{6}{|c|}{ Alcohol use during pregnancy } \\
\hline No & 5313 & 2302 & $43 \cdot 3$ & $1 \cdot 0$ & Ref. \\
\hline Yes & 655 & 350 & $53 \cdot 4$ & 1.5 & $1 \cdot 3,1 \cdot 8+$ \\
\hline \multicolumn{6}{|l|}{ BMI before pregnancy } \\
\hline$<25 \mathrm{~kg} / \mathrm{m}^{2}$ & 3961 & 1698 & $42 \cdot 9$ & $1 \cdot 0$ & Ref. \\
\hline $25-30 \mathrm{~kg} / \mathrm{m}^{2}$ & 1222 & 551 & $45 \cdot 1$ & $1 \cdot 1$ & $1 \cdot 0,1 \cdot 2$ \\
\hline$\geq 30 \mathrm{~kg} / \mathrm{m}^{2}$ & 436 & 211 & $48 \cdot 4$ & $1 \cdot 3$ & $1 \cdot 0,1 \cdot 5 t$ \\
\hline \multicolumn{6}{|l|}{ Physical activity $\geq 5 \mathrm{~d} /$ week } \\
\hline Yes & 2582 & 1123 & $43 \cdot 5$ & $1 \cdot 0$ & Ref. \\
\hline No & 3298 & 1472 & $44 \cdot 6$ & $1 \cdot 0$ & $0.9,1 \cdot 2$ \\
\hline
\end{tabular}

Ref., referent category.

*Denominator varies due to missing values for some variables (ninety-five for physical activity, 356 for BMI, and zero to twenty-one for remaining variables). tStatistically significant $(P<0.05)$.

¥Other religions include Humanism, Islam, Judaism, Hinduism and Buddhism.

The higher intake among subgroups of women indicates that there is room for improvement in groups with lower intake. We also found that women least likely to take supplementation are among the most vulnerable in Dutch society.

This DELIVER study showed that several sociodemographic factors were associated with not using folic acid before conception, in particular non-Western ethnicity and not having a partner. This is in line with previous research $^{(12,14-19)}$. In addition, our results showed that women who did not take folic acid supplements preconceptionally seemed to follow a less healthy lifestyle including smoking and drinking alcohol, and had a general moderate or poor health status. Interventions to improve 
Table 3 Factors associated with no preconception use of folic acid supplements, multilevel multivariable backward logistic regression analysis; DELIVER multi-centre, prospective, population-based cohort study, the Netherlands, 2009 and 2010

\begin{tabular}{|c|c|c|}
\hline \multirow[b]{2}{*}{ Characteristic } & \multicolumn{2}{|c|}{ No preconception use of folic acid” } \\
\hline & OR & $95 \% \mathrm{Cl}$ \\
\hline \multicolumn{3}{|l|}{ Age } \\
\hline$\leq 25$ years & $2 \cdot 0$ & $1 \cdot 7,2 \cdot 4 \dagger$ \\
\hline $26-35$ years & $1 \cdot 0$ & Ref. \\
\hline$\geq 36$ years & $1 \cdot 2$ & $1 \cdot 0,1 \cdot 4$ \\
\hline \multicolumn{3}{|l|}{ Partner } \\
\hline Yes & $1 \cdot 0$ & Ref. \\
\hline No & $2 \cdot 7$ & $1 \cdot 6,4 \cdot 6 \dagger$ \\
\hline \multicolumn{3}{|l|}{ Ethnicity } \\
\hline Dutch & $1 \cdot 0$ & Ref. \\
\hline Other Western & $1 \cdot 6$ & $1 \cdot 3,2 \cdot 0 t$ \\
\hline Non-Western & $2 \cdot 0$ & $1 \cdot 5,2 \cdot 7 \dagger$ \\
\hline \multicolumn{3}{|l|}{ Religion } \\
\hline None/don't want to say & $1 \cdot 0$ & Ref. \\
\hline Catholic & $1 \cdot 1$ & $0 \cdot 9,1 \cdot 3$ \\
\hline Protestant & $1 \cdot 4$ & $1 \cdot 2,1 \cdot 7 \dagger$ \\
\hline Other‡ & $1 \cdot 6$ & $1 \cdot 2,2 \cdot 3 t$ \\
\hline \multicolumn{3}{|l|}{ Educational level } \\
\hline Low & $1 \cdot 4$ & $1 \cdot 2,1 \cdot 7 \dagger$ \\
\hline Medium & $1 \cdot 2$ & $1 \cdot 1,1 \cdot 4 t$ \\
\hline High & $1 \cdot 0$ & Ref. \\
\hline \multicolumn{3}{|l|}{ Employed } \\
\hline Yes & $1 \cdot 0$ & Ref. \\
\hline No & $1 \cdot 9$ & $1 \cdot 6,2 \cdot 3+$ \\
\hline \multicolumn{3}{|l|}{ Parity } \\
\hline Nulliparous & $1 \cdot 0$ & Ref. \\
\hline Multiparous & 1.5 & $1 \cdot 4,1 \cdot 7 t$ \\
\hline \multicolumn{3}{|l|}{ General state of health } \\
\hline Excellent or (very) good & $1 \cdot 0$ & Ref. \\
\hline Moderate or poor & $1 \cdot 2$ & $1 \cdot 1,1 \cdot 5 t$ \\
\hline \multicolumn{3}{|c|}{ Ability to influence own health } \\
\hline Quite a lot or a lot & $1 \cdot 0$ & Ref. \\
\hline Not at all or hardly & $1 \cdot 3$ & $1 \cdot 1,1 \cdot 5 t$ \\
\hline \multicolumn{3}{|l|}{ Smoking during pregnancy } \\
\hline No & $1 \cdot 0$ & Ref. \\
\hline Yes & $1 \cdot 6$ & $1 \cdot 3,2 \cdot 0+$ \\
\hline \multicolumn{3}{|l|}{ Alcohol use during pregnancy } \\
\hline No & $1 \cdot 0$ & Ref. \\
\hline Yes & $1 \cdot 7$ & $1 \cdot 4,2 \cdot 0 t$ \\
\hline
\end{tabular}

Ref., referent category.

${ }^{*}$ No preconception folic acid use compared with preconception use ( $n 5879$, $1.6 \%$ missing values).

tStatistically significant $(P<0.05)$.

$\ddagger$ Other religions are Humanism, Islam, Judaism, Hinduism and Buddhism.

folic acid use should focus on reaching these risk groups to reduce health inequalities. One should bear in mind that provision of information alone might not be sufficient as a Dutch study showed that even of the women who had heard about folic acid before their pregnancy and were aware of the advised period, $26 \%$ did not take it ${ }^{(23)}$. A recent study from the USA revealed that reasons for not taking folic acid were morning sickness, busy lives, competing priorities for concern, poor memory, citing healthy pregnancy outcomes without supplement use, and scepticism about its preventive action ${ }^{(14)}$. This research suggested that women should be clearly informed about the benefits of folic acid supplementation, the importance of starting supplementation before conception, and the recommended period and dosage. The difficulty is that taking folic acid supplements adequately requires, among other things, behaviour change ${ }^{(24)}$. Of the women in our study population, 15\% thought that they could not at all or hardly influence their health by their own behaviour. Further research is warranted into barriers for adequate folic acid use in the Netherlands.

An alternative approach to increasing folic acid intake is through the fortification of foods. This approach has been widely used elsewhere and ensures that the majority of women will have adequate folic acid intake before conception, including those women who do not plan a pregnancy. Folic acid fortification of wheat flour has been implemented in the USA, Canada and seventy-three other countries worldwide ${ }^{(25)}$, and recent evidence demonstrates that food fortification programmes are highly effective in preventing NTD, with an estimated $46 \%$ reduction in NTD prevalence reported ${ }^{(8,22,24,26)}$. When compared with the $1.7 \%$ annual decrease reported in Europe in the period $2001-2010^{(27)}$, where no fortification is used, this population-based approach to fortification appears to have had a much more profound impact on NTD. In 2000, the Dutch Health Council advised against folic acid enrichment of food products because of possible masking of vitamin $\mathrm{B}_{12}$ deficit, which delays the diagnosis of vitamin $\mathrm{B}_{12}$ deficiency and can lead to irreversible neurological damage ${ }^{(28,29)}$. Therefore, folic acid fortification of wheat flour has not yet been implemented in the Netherlands. Co-fortification of staple foods with modest amounts of vitamin $\mathrm{B}_{12}$ can overcome this problem as previous research showed that this improves folate as well as vitamin $\mathrm{B}_{12}$ status in older people ${ }^{(30)}$. Besides, a more recent study found that increased intake of folic acid did not mask vitamin $\mathrm{B}_{12}$ deficiency in young adults $^{(31)}$. Also the currently used diagnostics to determine vitamin $\mathrm{B}_{12}$ deficiency (serum levels of vitamin $\mathrm{B}_{12}$ or methylmalonic acid instead of $\mathrm{Hb}$ levels and the size of red blood cells) abolishes the issue of masking of vitamin $\mathrm{B}_{12}$ deficit by folic acid. In 2008, the Dutch Health Council concluded that the folic acid intake of Dutch women who wish to become pregnant has increased but is still insufficient $^{(32)}$. Therefore, it advised to enrich bread and bread substitutes with folic acid while prohibiting voluntary fortification of other food products in order to reduce the risk of an intake above the safe upper limit. We believe that such a policy would provide good coverage to all women of childbearing age, regardless of ethnicity and dietary habits. Unfortunately, this is difficult to implement as it requires adjustment of European regulations.

In September 2010 the US Food and Drug Administration approved an oral contraceptive containing a folate, the first of its kind, which is developed to prevent pregnancy and simultaneously decrease the risk for NTD by increasing red blood cell folate levels (even until several weeks after quitting its use $)^{(33,34)}$. This might be advantageous for unplanned pregnancies as well as for women who get pregnant soon after stopping oral contraception. However, 
not all women of childbearing age would benefit from this as, for example, in the Netherlands only $40 \%$ of them use oral contraceptives ${ }^{(35)}$. The European Medicines Authority has not approved adding folate to any oral contraceptive so far.

The decrease in live birth NTD prevalence in many of the twenty countries that collaborated in the European epidemiological surveillance of congenital anomalies is mainly due to the increase in prenatal diagnosis and termination of affected pregnancies in these countries, while the total prevalence has not significantly decreased ${ }^{(13)}$. A strategy of prevention by folic acid as opposed to prenatal diagnosis and abortion should be considered as there are few such serious defects that can be so easily prevented in modern medicine. As one-time campaigns are unlikely to be effective, there is a need for long-term strategies and continuous educational campaigns aimed both at health professionals and women of fertile age.

When interpreting our results, one should consider that our study population comprised slightly more higheducated and fewer ethnic minority women than the general population. This may have resulted in an underestimation of the number of women who do not use folic acid supplements before conception. Our study limited recall bias by asking about folic acid use during the first trimester of pregnancy. However, a potential limitation is that our results are based on self-reported folic acid use before and during pregnancy. Since many women nowadays are aware of the adverse effects of inadequate folic acid use on the fetus, the self-reported folic acid use could have been an overestimation. However, a validation study in the Netherlands showed that self-reporting is a valid method for assessing folic acid supplement use ${ }^{(11)}$. Finally, a limitation of the present study was that we only had information on the use of folic acid before conception or not, but not on the exact moment when women started taking it. Therefore, we did not know whether they started using folic acid at least the recommended four weeks before conception.

Our study adds to previous studies through its prospective nationwide design, with folic acid use assessed on average halfway through the pregnancy, and multivariable analysis to assess the determinants of no preconception folic acid use. A strength of the present study was that we used data from a large prospective cohort study, including information on sociodemographic and lifestyle factors. This enabled inclusion of many potential determinants in the analyses.

\section{Conclusion}

Despite various campaigns in the past, the level of adequate folic acid intake before conception remains suboptimal in the Netherlands and below the government's goal. Consequently, the NTD prevalence has not decreased as much as in countries with wheat flour fortification. The Dutch public health initiatives could learn from the successes in other international jurisdictions. Several sociodemographic and lifestyle factors were associated with no preconception use of folic acid in the current study, of which nonWestern ethnicity and not having a partner had the largest effect size. Mandatory fortification of staple foods with folic acid should be reconsidered as it could improve the folate status of all women of childbearing age, including those groups of women who are unlikely to plan their pregnancies or to receive or respond to health promotion messages. This would contribute substantially to reducing the NTD prevalence and socio-economic inequalities in NTD prevalence.

\section{Acknowledgements}

Sources of funding: This study was funded by the Midwifery Academy Amsterdam and Groningen AVAG (1006167). The Midwifery Academy Amsterdam and Groningen AVAG had no role in the design, analysis or writing of this article. Conflicts of interest: M.C.C. served as advisor for Bayer on oral contraceptives plus folate at the European Medicines Authority and receives funding from ZonMw for a randomised controlled trial on the dosage and length of folic acid use. All other authors have no conflicts of interest. Ethical approval: The DELIVER study was approved by the Medical Ethics Committee of VU University Medical Center in Amsterdam, the Netherlands. Authors' contribution: E.S. was project leader of the DELIVER study. J.M., E.S. and E.K.H. originated the idea for this secondary analysis. J.M., A.d.J. and M.C.C. developed the data analysis plan. J.M. performed all analyses, which were checked by A.d.J. J.M. drafted the manuscript, and all authors read and corrected draft versions of the manuscript and approved the final manuscript.

\section{References}

1. Kondo A, Kamihira O \& Ozawa H (2009) Neural tube defects: prevalence, etiology and prevention. Int J Urol 16, 49-57.

2. Yi Y, Lindemann M, Colligs A et al. (2011) Economic burden of neural tube defects and impact of prevention with folic acid: a literature review. Eur J Pediatr 170, 1391-1400.

3. Greene ND \& Copp AJ (2009) Development of the vertebrate central nervous system: formation of the neural tube. Prenat Diagn 29, 303-311.

4. European Surveillance of Congenital Anomalies, EUROCAT Central Registry, University of Ulster (2012) Prevalence tables. http://www.eurocat-network.eu/accessprevalencedata/ prevalencetables (accessed May 2013).

5. Mohangoo AD, van der Pal-de Bruin KM \& Buitendijk SE (2010) Aangeboren afwijkingen in Nederland 1997-2008. Gebaseerd op de landelijke verloskunde en neonatale registraties (Congenital Anomalies in the Netherlands 1997-2008, Based On the National Obstetrical and 
Neonatal Registries). Report no. KvL/P\&Z 2010.090. Leiden: Netherlands Organisation for Applied Scientific Research TNO.

6. MRC Vitamin Study Research Group (1991) Prevention of neural tube defects: results of the Medical Research Council Vitamin Study. Lancet 338, 131-137.

7. Czeizel AE, Dudas I \& Metneki J (1994) Pregnancy outcomes in a randomised controlled trial of periconceptional multivitamin supplementation. Final report. Arch Gynecol Obstet 255, 131-139.

8. De-Regil LM, Fernandez-Gaxiola AC, Dowswell T et al. (2010) Effects and safety of periconceptional folate supplementation for preventing birth defects. Cochrane Database Syst Rev issue 10, CD007950.

9. Voorlichtingsbureau voor de voeding (1994) Prevention of Neural Tube Defects by Supplementation of Folic Acid. The Hague: Preventiefonds.

10. de Walle HE \& de Jong-Van den Berg LT (2008) Ten years after the Dutch public health campaign on folic acid: the continuing challenge. Eur J Clin Pharmacol 64, 539-543.

11. Sikkens JJ, van Eijsden M, Bonsel GJ et al. (2011) Validation of self-reported folic acid use in a multiethnic population: results of the Amsterdam Born Children and their Development study. Public Health Nutr 14, 2022-2028.

12. Timmermans S, Jaddoe VW, Mackenbach JP et al. (2008) Determinants of folic acid use in early pregnancy in a multi-ethnic urban population in The Netherlands: The Generation R study. Prev Med 47, 427-432.

13. European Surveillance of Congenital Anomalies, EUROCAT (2009) Special Report: Prevention of Neural Tube Defects by Periconceptional Folic Acid Supplementation in Europe. Belfast: EUROCAT Central Registry, University of Ulster.

14. Barbour RS, Macleod M, Mires G et al. (2012) Uptake of folic acid supplements before and during pregnancy: focus group analysis of women's views and experiences. J Hum Nutr Diet 25, 140-147.

15. de Jong-Van den Berg LT, Hernandez-Diaz S, Werler MM et al. (2005) Trends and predictors of folic acid awareness and periconceptional use in pregnant women. Am J Obstet Gynecol 192, 121-128.

16. McGuire M, Cleary B, Sahm L et al. (2010) Prevalence and predictors of periconceptional folic acid uptake prospective cohort study in an Irish urban obstetric population. Hum Reprod 25, 535-543.

17. Ray JG, Singh G \& Burrows RF (2004) Evidence for suboptimal use of periconceptional folic acid supplements globally. BJOG 111, 399-408.

18. Stockley L \& Lund V (2008) Use of folic acid supplements, particularly by low-income and young women: a series of systematic reviews to inform public health policy in the UK. Public Health Nutr 11, 807-821.

19. Van Vree F, Van der Kemp S \& Foets M (2003) Foliumzuurgebruik en gezond gedrag bij zwangerschap (Folic Acid Use and Health Behaviour during Pregnancy). Report no. B2581. Leiden: Research voor Beleid.
20. Manniën J, Klomp T, Wiegers T et al. (2012) Evaluation of primary care midwifery in The Netherlands: design and rationale of a dynamic cohort study (DELIVER). BMC Health Serv Res 12, 69.

21. Statistics Netherlands (2013) Definitions. http://www.cbs. nl/en-GB/menu/methoden/begrippen/default.htm?Languages witch $=$ on\&ConceptID $=315$ (accessed May 2013).

22. Botto LD, Lisi A, Robert-Gnansia E et al. (2005) International retrospective cohort study of neural tube defects in relation to folic acid recommendations: are the recommendations working? BMJ 330, 571.

23. de Walle HE, van der Pal KM, de Jong-Van den Berg LT et al. (1999) Effect of mass media campaign to reduce socioeconomic differences in women's awareness and behaviour concerning use of folic acid: cross sectional study. BMJ 319, 291-292.

24. Berry RJ, Bailey L, Mulinare J et al. (2010) Fortification of flour with folic acid. Food Nutr Bull 31, Suppl. 1, S22-S35.

25. Flour Fortification Initiative, USA (2012) Country profiles. http://www.ffinetwork.org/country_profiles/index.php (accessed May 2013).

26. Blencowe H, Cousens S, Modell B et al. (2010) Folic acid to reduce neonatal mortality from neural tube disorders. Int $J$ Epidemiol 39, Suppl. 1, i110-i121.

27. European Surveillance of Congenital Anomalies, EUROCAT (2010) EUROCAT Statistical Monitoring Report - 2010. Belfast: EUROCAT Central Registry, University of Ulster.

28. Health Council of the Netherlands (2000) Risico's van foliumzuurverrijking (Risks of Fortification with Folic Acid). Report no. 2000/21. The Hague: Health Council of the Netherlands.

29. Scientific Advisory Committee on Nutrition (2006) Folate and Disease Prevention. London: The Stationery Office.

30. Winkels RM, Brouwer IA, Clarke R et al. (2008) Bread cofortified with folic acid and vitamin B-12 improves the folate and vitamin B-12 status of healthy older people: a randomized controlled trial. Am J Clin Nutr $\mathbf{8 8}$, 348-355.

31. Mills JL, Carter TC, Scott JM et al. (2011) Do high blood folate concentrations exacerbate metabolic abnormalities in people with low vitamin B-12 status? Am J Clin Nutr $\mathbf{9 4}$, 495-500.

32. Health Council of the Netherlands (2008) Naar een optimal gebruik van foliumzuur (Towards An Optimal Use of Folic Acid). Report no. 2008/02. The Hague: Health Council of the Netherlands.

33. US Food and Drug Administration (2010) FDA approves combination contraceptive containing a folate. http://www. fda.gov/NewsEvents/Newsroom/PressAnnouncements/ucm22 7237.htm (accessed May 2013).

34. Fruzzetti F (2012) Beyaz ${ }^{\circledR}:$ an oral contraceptive fortified with folate. Womens Health $8,13-19$.

35. Picavet C, van der Leest L \& van der Vlugt I (2011) Contraceptive Decision-Making: Background and Outcomes of Contraceptive Methods. Utrecht: Rutgers FPW. 